\title{
Efeitos infringentes dos embargos de declaração
}

\author{
Thales Fernando Lima ${ }^{1}$
}

\section{Resumo}

\begin{abstract}
Analisa o tratamento doutrinário e jurisprudencial dispensado aos embargos de declaração quando o seu acolhimento importar em alteração substancial da decisão embargada.
\end{abstract}

Palavras-Chave: Embargos de declaração; Efeitos modificativos; Efeitos infringentes; Princípio do contraditório.

\section{Introdução}

Os embargos de declaração, a teor do art. 535, I e II, do CPC, são o recurso cabível quando, na sentença ou o acórdão, houver obscuridade, contradição, ou omissão sobre ponto de que deveria pronunciar-se o juiz ou tribunal. A despeito da redação do aludido dispositivo, é firme o entendimento de que os embargos de declaração também podem ser manejados contra decisões interlocutórias, sempre quando presentes os vícios que the constituem fundamento. Também são cabíveis quando a decisão, a despeito de rotulada de "despacho de mero expediente", for suscetível de causar gravame à parte ou ao interessado. $^{2}$

Eles devem ser opostos no prazo de 5 (cinco) dias, em petição dirigida ao juiz ou relator da causa, com a indicação do ponto obscuro, contraditório ou omisso, não estando sujeitos a preparo (CPC, art. 536).

São dotados de efeito suspensivo, na medida em que suspendem a eficácia da decisão embargada. Também interrompem o prazo para a interposição de outros recursos, por qualquer das partes (CPC, art. 538). A interrupção quer dizer que as partes, após a

1 Aluno do 4o ano do Curso de Graduação em Direito da Universidade Estadual de Londrina. E-mail: thalesthales@sercomtel.com.br.

2 "Os embargos declaratórios são cabíveis contra qualquer decisão judicial e, uma vez interpostos, interrompem o prazo recursal. A interpretação meramente literal do art. 535 do Código de Processo Civil atrita com a sistemática que deriva do próprio ordenamento processual, notadamente após ter sido erigido a nível constitucional o princípio da motivação das decisões judiciais" (EREsp 159317/DF, Rel. Min. Sálvio de Figueiredo Teixeira, Corte Especial, julgado em 07.10.1998, DJ 26.04.1999 p. 36). 
intimação da decisão que julgou embargos, terão novo prazo por inteiro para a interposição do recurso originariamente cabível.

Discute-se, por outro lado, se os embargos de declaração teriam efeito devolutivo, já que eles não são dirigidos a órgão diverso, geralmente superior, daquele que proferiu a decisão embargada. Ora, o efeito devolutivo dos recursos nada tem que ver com o fato de o órgão destinatário do inconformismo ser hierarquicamente superior àquele de onde proveio a decisão inquinada. Para a configuração de tal efeito, portanto, basta que a matéria seja devolvida ao Poder Judiciário para reapreciação, pouco importando isso seja feito ao mesmo órgão prolator da decisão recorrida (WAMBIER, 2002, p. 733).

Cumpre ainda salientar, que embora os embargos não tenham o escopo de alteração substancial da decisão embargada, e bem por isso alguns doutrinadores não lhes reconhece a natureza de recurso (AMARAL SANTOS, 2003, p. 152), excepcionalmente eles podem levar à modificação (infringência) daquela, e não simplesmente à sua aclaração ou integração como ordinariamente acontece. Diz-se, nesses casos, que os embargos de declaração assumem efeitos modificativos ou infringentes, tema objeto de desenvolvimento nas linhas que seguem.

\section{Efeitos modificativos}

É tradicional a assertiva segundo a qual a decisão proferida em sede de embargos de declaração deve se limitar a declarar o conteúdo da decisão embargada, não podendo, por isso, inovar na essência. Segundo Francisco Cavalcanti Pontes de Miranda (1999, p. 399400), "o que se pede é que se declare o que foi decidido, porque o meio empregado para exprimi-lo é deficiente ou impróprio. Não se pede que se redecida; pede-se que reexprima".

Todavia, considerável parte da doutrina sustenta que tal entendimento, se tomado em termos absolutos, na prática pode acarretar graves distorções e injustiças. Esse é motivo pelo qual são cada vez maiores as decisões no sentido de admitir a força modificativa dos embargos declaratórios em casos especiais e em caráter excepcional. Não é por acaso, pois, que o SUPREMO TRIBUNAL FEDERAL vem reiteradamente decidindo que "os embargos de declaração não constituem meio processual cabível para reforma do julgado, não sendo possível atribuir-lhes efeitos infringentes, salvo em situações excepcionais" ( RE-AgR-ED 198131/SP, 2006, p. 35). 
Egas Moniz Dirceu de Aragão, citado por Luiz Guilherme Marinoni e Sérgio Cruz Arenhart (2006, p. 559), bem explica esse fenômeno:

\begin{abstract}
ninguém contesta que os embargos de declaração não visam a modificar o julgamento; não é possível que, por seu intermédio, a proposição ' $a$ ', por estar errada ou ser injusta, venha a ser substituída pela proposição ' $b$ ', tida por certa ou justa - isso seria objeto de julgamentos em grau de recurso. Mas é evidente que, se o julgamento contiver, simultaneamente, afirmações excludentes entre si, urge que uma delas seja afastada (quiçá ambas, para dar lugar a uma terceira), e isso só se faz, obviamente, modificando o próprio julgamento, a fim de, expungida a contradição, torná-lo coerente. Por conseguinte, a velha e corriqueira afirmação, às vezes repetida sem meditação, de não ser permitido 'modificar' o julgamento através de embargos de declaração precisa ser entendida com argúcia.
\end{abstract}

Por óbvio, em decorrência de sua finalidade - eliminar obscuridade e contradição, bem como suprir omissão -, os embargos declaratórios não podem ser acolhidos se manejados com manifesto propósito de alteração do julgado. O efeito infringente, para ser legítimo, só terá lugar quando a alteração da decisão for conseqüência necessária do acolhimento dos embargos. Assim, consoante ensinamentos de Nelson Nery Junior e Rosa Maria de Andrade Nery (2004, p. 1014), “a infringência do julgado pode ser apenas a conseqüência do provimento dos EDcl, mas não o seu pedido principal, pois isso caracteriza pedido de reconsideração, finalidade estranha aos EDcl". Arrematam, mais adiante, que "o objetivo e a finalidade dos embargos não podem ser a infringência; esta encontra-se o momento posterior ao do julgamento do mérito dos embargos: na conseqüência decorrente daquilo que já foi julgado". A propósito, não foi outro o motivo que levou o e. STJ a decidir que "a possibilidade de atribuição de efeitos infringentes ou modificativos a embargos de declaração sobrevém como resultado da presença de omissão, obscuridade ou contradição a serem corrigidas no acórdão embargado, e não da simples interposição do recurso" (Edcl no AgRg, Resp 681.728/MS, DJ 12.03.2007, p. 312).

\title{
3 Hipóteses de modificação do julgado
}

Anotam Nelson Nery Júnior e Rosa Maria de Andrade Nery (2004, p. 1024) que "Os EDcl podem ter, excepcionalmente, caráter infringente quando utilizados para: a) correção de erro material manifesto; b) suprimento de omissão; c) extirpação de contradição". 
Haverá omissão, quando alguma questão posta sub judice deixar de ser apreciada pelo juiz ou tribunal. Exemplo clássico lembrado pela doutrina é o caso em que o juiz deixa de apreciar a alegação de prescrição formulada em contestação, condenado, de conseguinte, o réu ao pagamento dos valores pleiteados. Entretanto, há quem alegue, que nessa hipótese, a decisão de mérito estaria implícita, mas não omissa. Essa é a tese defendida por Ernane Fidélis dos Santos (2003, p. 614), consoante a qual "o julgamento de procedência importa negar a prescrição, mesmo que sobre ela o juiz não se tenha pronunciado".

Suprida a omissão, pode ocorrer que o deslinde da causa tome rumo totalmente diverso do qual se decidira, podendo a sentença, que antes era pela procedência do pedido, passar a ser de improcedência, ou vice-versa. Nelson Nery Júnior e Rosa Maria de Andrade Nery (2004, p. 1014) asseveram que "na verdade não haverá propriamente infringência do julgado, mas decisão nova, pois a matéria não foi objeto de consideração pela decisão embargada".

É freqüente, também, a ocorrência de efeitos infringentes quando os embargos são opostos com a finalidade de espancar contradição. Tal vício, explicam Luiz Guilherme Marinoni e Sérgio Cruz Arenhart (2006, p. 556), “decorre da justaposição de fundamentos antagônicos, seja com outros fundamentos, seja com a conclusão, seja com o relatório (quando houver, no caso de sentença ou acórdão), seja, ainda, no caso de julgamento de tribunais, com a ementa da decisão". Por tal motivo, eliminando-se alguma das proposições antagônicas, poderá haver substancial alteração do julgado (STJ - EDcl, Edcl, AgRg, Ag 600.879/DF, DJ 26.09.2005, p. 437).

A obscuridade, por seu turno, é o atributo do que não está claro (FERREIRA FILHO, 2001, p. 300). Nesse caso, a alteração do julgado se mostra pouco comum, já que o juiz se restringirá a aclarar o ponto obscuro. Bem por isso, ressalta José Carlos Barbosa Moreira (2006, p. 546): "na hipótese de obscuridade, realmente, o que faz o novo pronunciamento é só esclarecer o teor do primeiro, dando-Ihe interpretação autêntica".

Vislumbra-se, ainda, a infringência da decisão em casos de equívoco manifesto ou erro material. Assim, por exemplo, podem os embargos ser acolhidos para corrigir declaração manifestamente errônea de intempestividade da apelação (NERY; NERY, 2004, p. 
1014), ou para anular acórdão que, por equívoco, julgou o recurso especial inadimitido na origem (STJ - Edcl, REsp no 606.384 - SP, 15.02.2007).

Sendo caso de erro material, portanto, são cabíveis os embargos. E mais: mesmo se decorrido o prazo para sua oposição, aquele vício ainda poderá ser argüido, uma vez que o art. 463, I, do CPC, autoriza o juiz, de ofício ou a requerimento da parte (por simples petição), corrigir inexatidões, ou retificar erros de cálculo verificados na sentença.

Não se deve, todavia, confundir erro material com erro de fato. 0 erro material e o erro de cálculo, vícios de menor gravidade, estão previstos no dispositivo legal supracitado, podendo o julgador de ofício proceder a sua corrigenda. Já o erro de fato, verdadeiro erro de julgamento (FERREIRA FILHO, 2001, p.331), cujo conhecimento, por isso, reclama novo exame da prova, importa em admitir um fato inexistente, ou considerar inexistente um fato efetivamente ocorrido (CPC, art. 485, $\S 10$ ).

Nada obstante, a jurisprudência do STJ vem amplamente emprestando efeitos infringentes aos embargos de declaração quando a correção desse vício acarretar, necessariamente, a modificação do decisum. ${ }^{3}$

Atualmente não é mais possível a utilização dos embargos de declaração com o objetivo de eliminar dúvida, porque essa possibilidade foi excluída do CPC com o advento da Lei n.o 8.950/94, que deu nova redação ao inciso I do art. 535. Tampouco se prestam os embargos para responder consultas formuladas pelas partes. ${ }^{4}$

Luiz Orione Neto (2002, p. 451) admite sejam os embargos declaratórios opostos com vistas a argüição de matérias de ordem pública, independentemente da existência ou não de omissão na decisão. O fato é que, como não existe preclusão no concernente às matérias de ordem pública, elas poderão ser objeto de conhecimento em qualquer tempo ou grau de jurisdição, independentemente de expressa manifestação das partes (efeito

\footnotetext{
3 "É admitido o uso de embargos de declaração com efeitos infringentes, em caráter excepcional, para a correção de premissa equivocada, com base em erro de fato, sobre a qual tenha se fundado o acórdão embargado, quando tal for decisivo para o resultado do julgamento" (EDcl no REsp 599653/SP, 3a Turma, Min. Nancy Andrighi, DJ de 22.08.2005).

4 Conforme já assentou o STJ, "Não cabe ao Tribunal, que não é órgão de consulta, responder a 'questionários' postos pela parte sucumbente, que não aponta de concreto nenhuma obscuridade, omissão ou contradição no acórdão, mas deseja, isto sim, esclarecimentos sobre sua situação futura e profliga o que considera injustiças decorrentes do decisum (...)" (EDcl no REsp n. 739/RJ, Relator Ministro Athos Carneiro, DJ de 12.11.90).
} 
translativo). Dessa forma, no julgamento da apelação, o Tribunal poderá, de ofício, delas conhecer.

Nesse passo, é corrente o entendimento segundo o qual a não-preclusão das matérias de ordem pública ocorre somente nas instâncias ordinárias, pois em sede de recurso e especial e recurso extraordinário, elas não poderão ser apreciadas se ausente o necessário requisito do pré-questionamento, conforme enunciado das Súmulas n.o 211 do STJ e n.ㅇ 282 do STF.

\section{Da observância do contraditório}

Ordinariamente, no procedimento dos embargos de declaração, não se abre vista à parte contrária para manifestação, porquanto por meio desse recurso não se busca uma nova decisão sobre a causa, mas sim o aperfeiçoamento da decisão já proferida. Todavia, em observância ao princípio do contraditório, sempre que presente a possibilidade de modificação da decisão pelo manejo dos embargos, será necessária a abertura de prazo à parte contrária para reposta. Assentou, por isso, o STF que "visando os embargos declaratórios à modificação do provimento embargado, impõe-se, considerado o devido processo legal, a ciência da parte contrária para, querendo, apresentar contra-razões" (HC 74735/PR, DJ 16.05.1997, p. 19951). Do mesmo entendimento compartilha o Superior Tribunal de Justiça (REsp 491311/MG, DJ. 09.06.2003, p. 189).

Em sentido contrário, já decidiu o e. Tribunal Regional Federal da 4 a Região, em aresto cuja ementa restou vazada nos seguintes termos:

PROCESSUAL CIVIL. EMBARGOS DE DECLARAÇÃO. INEXISTÊNCIA DE SEUS LEGAIS PRESSUPOSTOS. REJEIÇÃO. EFEITOS INFRINGENTES A RECURSO ACLARATÓRIO ANTERIOR - NÃO-OFENSA AO CONTRADITÓRIO. "A concessão de efeitos infringentes a embargos de declaração não ofende ao princípio do contraditório e da ampla defesa, desnecessária a intimação da parte contrária em momento anterior ao julgamento. Diligência que a lei processual regente não indica, tampouco a jurisprudência pátria é uníssona no sentido" (TRF4, EDAG 2001.04.01.089766-9, Quarta Turma, Relator Amaury Chaves de Athayde, publicado em 24/11/2004).

Adotando posição intermediária, Manoel Caetano Ferreira Filho (2001, p. 318) sustenta que: 
Nos casos em que a modificação decorre do afastamento da contradição ou do suprimento da omissão, como 'apenas conseqüência do provimento' dos embargos declaratórios, a ausência do contraditório parece não ter maior gravidade, uma vez que as partes já debateram, ou tiveram a oportunidade de debater a matéria que Ihes constitui o objeto. No entanto, quando se pretende verdadeiro efeito modificativo, por ocorrência de 'erro manifesto' ou de manifesta nulidade, não se pode dispensar o contraditório. Imagine-se a hipótese em que o recorrido tenha alegado, e o tribunal acolhido, intempestividade do recurso ou do seu preparo, concluindo, pois, pelo seu não conhecimento. Não poderá, depois, ser simplesmente surpreendido por nova decisão, proferida nos embargos declaratórios, que tenha modificado a anterior e, assim, admitido o recurso.

Infere-se, portanto, prevalecer a tese de que, presente a possibilidade de efeito infringente, deva o julgador, antes de proferir decisão, conceder vista dos autos à parte contrária para resposta. Anote-se, a abertura de vista para contra-razões decorre da mera possibilidade do acolhimento dos embargos. E, à míngua de disposição legal, entende-se que o prazo para manifestação da parte "embargada" deve ser o mesmo previsto para a interposição dos embargos de declaração, isto é, 5 (cinco) dias, de acordo com o art. 536 do CPC.

\section{Conclusão}

Conforme o exposto, a atribuição de efeitos infringentes aos embargos de declaração, como conseqüência necessária do acolhimento destes, em nada atenta contra a sistemática de recursos do CPC. Pelo contrário, é por ele autorizado expressamente em seu art. 463, II. Força é convir, ademais, que tal procedimento encontra-se em consonância com os princípios da economia e celeridade processual, não podendo, por isso, a parte sofrer um gravame ao ver postergada a entrega da prestação jurisdicional a que tem direito, por falha imputável exclusivamente ao órgão judicante. Não há, pois, que se perder de vista que o processo é instrumento, sendo sua tarefa, justamente, conferir a alguém, por intermédio do Estado-juiz, a reparação de um dano sofrido.

\section{Referências}

ALVIM, Eduardo Arruda. Curso de direito processual civil. São Paulo: Editora Revista dos Tribunais, 2000. v. 2. 
AMARAL SANTOS, Moacyr. Primeiras Linhas de direito processual civi. 21. ed. São Paulo: Saraiva, 2003. v. 3.

BARBOSA MOREIRA, José Carlos. Comentários ao Código de Processo Civil. 13. ed. Rio de Janeiro: Forense, 2006. v. 5.

FERREIRA FILHO, Manoel Caetano. Comentários ao Código de Processo Civil, volume 7: do processo de conhecimento, arts. 496 a 565. Coordenação de Ovídio Araújo Baptista da Silva. São Paulo: Editora Revista dos Tribunais, 2001.

MARINONI, Luiz Guilherme e ARENHART, Sérgio Cruz. Manual do processo de conhecimento. 5. ed. São Paulo: Editora Revista dos Tribunais, 2006.

NERY JUNIOR, Nelson; NERY ANDRADE, Rosa Maria de. Código de processo civil comentado e legislação extravagante. 8. ed. São Paulo: Editora Revista dos Tribunais, 2004.

NERY JUNIOR, Nelson. Princípios fundamentais: teoria geral dos recursos. 5. ed. São Paulo: Editora Revista dos Tribunais, 2000.

ORIONE NETO, Luiz. Recursos cíveis: teoria geral, princípios no âmbito recursal, da ordem dos processos no tribunal. São Paulo: Saraiva, 2002.

PONTES DE MIRANDA, Francisco Cavalcanti. Comentários ao Código de Processo Civil. Rio de Janeiro: Forense, 1999. v. 7.

SANTOS, Ernane Fidélis dos. Manual de direito processual civil. 10. ed. São Paulo: Saraiva, 2003. v. 1.

WAMBIER, Luiz Rodrigues; ALMEIDA, Flávio Renato de; TALAMINI, Eduardo. Curso Avançado de Processo Civil. 4. ed. São Paulo: Editora Revista dos Tribunais, 2002. v. 1. 